\title{
INICIAÇÃO CIENTÍFICA PARA ALUNOS DA EDUCAÇÃO BÁSICA: UMA PESQUISA-AÇÃO EM ESCOLAS PÚBLICAS PAULISTAS
}

\author{
Roger Marchesini de Quadros Souza ${ }^{1}$ \\ José Cláudio Diniz Couto ${ }^{2}$ \\ Luzia Serapicos Martins Diniz Couto ${ }^{3}$
}

\section{Resumo}

Este artigo apresenta a trajetória e a pesquisa realizada em duas escolas públicas de Educação Básica, com base em um Projeto de Iniciação Científica (PIC) desenvolvido com alunos dos anos finais do Ensino Fundamental e do Médio, antes e durante a pandemia de COVID-19. A metodologia utilizada foi a da pesquisa-ação, o processo iniciou-se com alunos dos anos finais da educação básica no ano de 2019 e se ampliou, em 2020, para alunos do Ensino Médio. O processo de orientação da Iniciação Científica iniciou-se em 2019, de forma exclusivamente presencial e, ao longo do ano de 2020, com a chegada da pandemia e decretação da quarentena no Estado de São Paulo, passou a se realizar de forma remota. Neste trabalho, apresentamos aspectos da realização da pesquisa e a trajetória dos Projetos de Iniciação Científica desenvolvidos com os alunos da Educação Básica.

Palavras-chave: Iniciação Científica. Educação Básica. Pesquisa-Ação. Pandemia. Pesquisa em educação.

\section{SCIENTIFIC INITIATION FOR BASIC EDUCATION STUDENTS: AN ACTION- RESEARCH IN PUBLIC SCHOOLS IN SÃO PAULO}

\begin{abstract}
This article presents the trajectory and research realized in two public schools of basic education based on a Scientific Initiation Project (PIC) developed with students from the final years of elementary and high school, before and during the COVID-19 pandemic. The methodology used is the action-research, the process started with students from the final years of basic education in 2019 and expanded, in 2020, to high school students. The Scientific Initiation orientation process started in 2019 exclusively in presential model and throughout the year of 2020, with the arrival of the pandemic and the decree of quarantine in the state of São Paulo, began to happen remotely. In this study we present aspects of the research and the trajectory of the Scientific Initiation Projects developed with the students of basic education.
\end{abstract}

Keywords: Action-research. Scientific Initiation. Basic Education. Pandemics. Education Research.

\section{Introdução}

Nesta investigação, relatamos o desenvolvimento de um projeto de Pesquisa-Ação desenvolvido por integrantes do Grupo de Estudos e Pesquisas Sociais e Políticas em Fracasso Escolar - GEPESP, que se refere ao desenvolvimento de Projetos de Iniciação Científica realizados junto a alunos da Educação Básica de duas escolas públicas na Baixada Santista,

\footnotetext{
${ }^{1}$ Pesquisador Coordenador do Grupo de Estudos e Pesquisas Sociais e Políticas em Fracasso Escolar - GEPESP.

${ }^{2}$ Pesquisador do Grupo de Estudos e Pesquisas Sociais e Políticas em Fracasso Escolar - GEPESP.

${ }^{3}$ Pesquisadora do Grupo de Estudos e Pesquisas Sociais e Políticas em Fracasso Escolar - GEPESP.
} 
região litorânea do Estado de São Paulo. A escola na qual se desenvolveu o Projeto com alunos do Ensino Fundamental é uma escola municipal, já a escola em que se aplicou o Projeto para os alunos do Ensino Médio é estadual e integrante do Programa de Ensino Integral (PEI).

A opção pela metodologia no modelo da pesquisa-ação deu-se em virtude da intenção de que os pesquisadores interagissem dinamicamente e desenvolvessem com os alunos desse nível de ensino, projetos de iniciação científica. O ponto de partida dessa pesquisa foi a indagação de em que medida o aluno dessa etapa de ensino é capaz de desenvolver uma pesquisa científica utilizando os critérios e metodologias científicas. Parte-se da hipótese de que a capacidade produtiva do estudante dos anos finais do Ensino Fundamental e do Ensino Médio está vinculada ao estágio de desenvolvimento de seus conhecimentos e habilidades. Nessas condições, com base na metodologia adotada, os professores da Educação básica teriam a possibilidade de desenvolver um papel de incentivadores da formação de pesquisadores, atuando como orientadores das pesquisas a serem efetivadas pelos alunos.

Consideramos ainda que o modelo de Pesquisa-Ação possibilita inserção do pesquisador como sujeito atuante da e na investigação. Assim, concordando com Thiollent, essa modalidade de pesquisa exige grande atenção e respeito aos caminhos percorridos pelos sujeitos da pesquisa, "Na pesquisa-ação, os pesquisadores desempenham um papel ativo no equacionamento dos problemas encontrados, no acompanhamento e na avaliação das ações desencadeadas em função dos problemas" (THIOLLENT, 1986, p. 15) e o desenvolvimento de um modelo participativo nas relações entre os envolvidos na pesquisa. Contudo, ao pesquisador, além de participar ativamente do desenvolvimento da ação no campo, cabe planejar e organizar seu desenvolvimento, portanto, não se trata de um modelo em que os eventos ocorrem aleatoriamente e sem controle ou de forma imprevisível, as ações são planejadas e reavaliadas cuidadosamente a cada passo, exigindo, assim, acompanhamento atento e preciso do seu desenvolvimento.

Destacamos que, no tocante ao respeito aos preceitos éticos, foram rigorosamente observados, especialmente sobre o esclarecimento da metodologia, desenvolvimento e objetivos, além de ser facultada a saída dos participantes a qualquer momento de sua realização. Todos os participantes dessa pesquisa, incluindo alunos e voluntários, participaram observando-se o princípio da cooperação e colaboração, conforme a classificação de Tripp (2005) sobre a participação em um projeto de pesquisa-ação:

Cooperação: quando um pesquisador consegue que alguém concorde em participar de seu projeto, a pessoa que coopera trabalha como parceiro sob muitos aspectos (uma vez que é regularmente consultado), mas em um projeto que sempre "pertence" ao pesquisador (o "dono" do projeto). A maioria das pesquisas para dissertação é desse tipo. Colaboração: quando as pessoas trabalham juntas como copesquisadores em um projeto no qual têm igual participação. (TRIPP, 2005, p. 455).

No início da pesquisa, todos os alunos participantes foram informados de que a atividade não seria computada para nota em nenhuma disciplina formal e que poderiam optar por deixar de participar da pesquisa a qualquer momento, caso quisessem. Em concordância com Tripp (2005), considera-se que a participação ativa dos alunos e voluntários poderia colocá-los na situação de coautores. 
Verificou-se, com o desenvolvimento da pesquisa, que o papel do orientador que atua com os alunos da Educação Básica, tanto nos anos finais do Ensino Fundamental como do ensino médio é muito trabalhoso. Dispende-se muito tempo de preparação e dedicação para dirimir dúvidas, esclarecer e orientar a realização de todas as tarefas. O planejamento precisa ser cuidadoso na organização dos tempos e espaços, pois as atividades não devem se prolongar demais, para que os participantes não percam o foco, e, ao final, apresentem resultado insatisfatório em relação às suas próprias expectativas, se frustrem e desistam da participação na pesquisa. No processo de orientação, o coordenador dos trabalhos precisa regularmente lembrar prazos, acompanhar, estimular e participar ativamente, seguindo e orientando as pesquisas desenvolvidas pelos alunos.

No caso da pesquisa desenvolvida, a população-alvo constituiu-se de alunos do nono ano do Ensino Fundamental de uma escola municipal da Baixada Santista, e alunos da segunda série do ensino médio de uma escola pública estadual localizada em outro município da mesma região. Nos dois casos, objetivou-se o desenvolvimento de Projetos de Iniciação Científica investigando o desenvolvimento do protagonismo dos alunos na produção de conhecimento que poderia propiciar aos alunos envolvidos o desenvolvimento do senso crítico, da capacidade de atuar em equipes, da leitura e escrita formais em consonância com o conjunto de leis que envolvem a Educação brasileira, especialmente, o inciso V do artigo 214, combinado com o inciso III do artigo 216, e o artigo 218, da Constituição Federal de 1988. Finalmente, tratou-se de uma pesquisa de campo aplicada em escolas públicas de Educação Básica que não adotam regularmente um modelo mais completo de programas de iniciação científica com seus alunos, o que a torna o estudo original pelo seu objeto e metodologia adotados.

O Projeto de Iniciação Científica (PIC), dirigido a alunos do Ensino Médio, foi realizado em uma escola pública da Baixada Santista no Estado de São Paulo, que foi integrada ao Programa de Ensino Integral no início de 2020.

O sonho da construção de uma escola de Educação Integral, que oferecesse uma formação de qualidade para toda a população brasileira é defendido desde os anos da década de 1930 pelos educadores e intelectuais defensores da proposta educacional denominada Escola Nova. Porém, esse ideal nunca foi realizado como política pública nacional, sendo materializado apenas em iniciativas esparsas como a do educador Anísio Teixeira, que inaugurou, em 1951, na Bahia, a primeira experiência pública de Educação Integral no Brasil, o Centro Carneiro Ribeiro. Assim, seguindo os pressupostos de Teixeira, em 1985, Darcy Ribeiro, também renomado educador, criou outra proposta no Rio de Janeiro, os Centros Integrados de Educação Pública (CIEP's), e mais tarde, em São Paulo, a criação do Centro de Educação Unificado (CEU's), em 2001. (VALENTINI; ZUCCHETTI, 2017)

Com esse panorama, durante o século XX, discutiu-se a implantação de uma Escola de Tempo Integral como alternativa viável para a educação pública do ponto de vista operacional, a fim de atender aos alunos das camadas populares e que poderia criar um ambiente favorável ao desenvolvimento da tão almejada educação integral. Especificamente no Estado de São Paulo, em 2012, foi implantado o Programa de Ensino Integral Paulista (PEI) em dezesseis escolas do ensino médio, com a proposta de valorização da profissão docente e da promoção de uma nova forma de organização escolar na rede de ensino público paulista com a adoção da escola de tempo Integral. Em seu início, o programa contou com maior dotação orçamentária, prevendo as necessidades dos alunos que teriam que permanecer mais tempo no interior da 
escola, mas, dessa vez, contando com atividades diferenciadas no contraturno ao destinado à denominada educação regular.

Ao longo dos últimos oito anos, a Secretaria de Educação do Estado de São Paulo tem intensificado seus esforços no sentido de instituir em maior número de unidades o Programa de Ensino Integral, chegando, no ano de 2020, a $664^{4}$ escolas oferecendo ao aluno mais tempo diário na escola, tendo como principal objetivo formar o jovem protagonista, autônomo, solidário e competente, com excelência acadêmica atendendo à Base Nacional Comum Curricular (BNCC).

\section{A Pesquisa-ação desenvolvida com alunos do Ensino Fundamental em 2019}

A Escola pública municipal, em que foi realizada a pesquisa no ano de 2019, localizase no Estado de São Paulo, na região da Baixada Santista. A unidade escolar foi criada na década de 1970, quando o bairro em que se localiza foi formado, sendo habitado principalmente por trabalhadores portuários e industriários e por grande contingente de migrantes nordestinos.

A instituição constitui-se como referência positiva na comunidade, desfrutando de muito prestígio na região em que se localiza e muitos dos docentes trabalham nela desde sua inauguração. Quando foi projetada, a escola atendia perfeitamente à demanda, no entanto, com o crescimento do bairro, a escola perdeu a capacidade espacial para atender à procura de vagas, já que, por ser uma escola muito demandada pela sua qualidade e em virtude desse crescimento, suas turmas são muito numerosas. Também, para acolher o crescente número de matrículas, foram construídas novas salas de aulas e, em função disso, pouco espaço livre sobrou do terreno original, estando quase todo ocupado por prédios, sobrando pouco espaço para atividades ao ar livre que envolvam os alunos ou a comunidade escolar. Em virtude desse panorama, a prefeitura do município cede eventualmente um anfiteatro de sua propriedade, ao lado do qual se localiza a quadra de esportes da escola, para que a instituição possa desenvolver atividades que incluam grande número de participantes.

O processo de pesquisa iniciou-se em uma negociação com a gestão da escola e um dos pesquisadores do GEPESP, que é professor na referida escola. Como resultado, ficou definido que a participação dos alunos seria voluntária, não seriam atribuídas notas às atividades que não integrariam o processo de avaliação regular dos alunos e que as atividades seriam desenvolvidas em duas aulas semanais do professor, equivalente ao período de cem minutos, encontros presenciais na biblioteca, mais orientações extras que poderiam utilizar meios eletrônicos de comunicação, como e-mail, WhatsApp e redes sociais.

Participaram das atividades de campo desse projeto, pesquisadores do GEPESP, dois professores efetivos da escola, dois voluntários, que cursam graduação na Universidade Católica de Santos, sendo um que já atuava como estagiário na unidade escolar e outro que era conhecido dos pesquisadores e se dispôs a participar assim que soube da iniciativa. A presença de ambos os voluntários contribuiu decisivamente para que o desenvolvimento do Projeto de Iniciação Científica (PIC) aplicado aos alunos do nono ano atingisse a maioria dos objetivos inicialmente propostos.

\footnotetext{
${ }^{4}$ Esse número representa cerca de $12 \%$ das escolas da rede pública estadual de São Paulo.
} 
Assim, essa pesquisa foi desenvolvida com base na aplicação de Projeto de Iniciação Científica (PIC) envolvendo uma classe de nono ano do Ensino Fundamental de escola pública, com o uso da metodologia da pesquisa-ação. O projeto foi oferecido às classes de nonos anos, tendo apenas uma delas aceitado o desafio após se inteirar dos objetivos e atividades previstas no cronograma de desenvolvimento da pesquisa montado pelo professor orientador. Desde o princípio, estabeleceu-se livre diálogo entre os envolvidos, que foi facilitador dos procedimentos de investigação. A faixa etária dos alunos participantes era dos treze aos catorze anos. Assim, o PIC foi desenvolvido com uma classe de nono ano, respeitando as condições acordadas com a direção da escola.

Iniciou-se, então, o processo de orientação que tratou dos temas, das metodologias, das principais referências teóricas, com a finalidade de que os alunos pudessem iniciar sua organização em grupos, as primeiras leituras e posteriores discussões. O processo de orientação iniciou-se com a exposição de várias temáticas que poderiam ser tratadas pelos alunos, constituindo diversas pautas que poderiam abrir várias frentes de pesquisa. Após essa etapa inicial, foram escolhidos pelos alunos seis temas, tendo sido formados cinco grupos de pesquisa e um aluno optou por atuar individualmente com o tema que escolheu. Todos os alunos participaram desses momentos e puderam opinar debatendo com seus pares e com o professor orientador, que é integrante do Grupo de Pesquisa que desenvolve esse projeto. Nesse período, destacou-se a presença dos pesquisadores voluntários especialmente da estudante de último ano de História, que realizou uma roda de conversa com os alunos participantes do PIC, propondo como tema o feminismo, assunto também trabalhado por uma das equipes. Nos encontros seguintes, os grupos receberam orientações definindo suas opções metodológicas, os fundamentos de suas pesquisas e as referências bibliográficas que seriam adotadas. Os temas escolhidos pelos alunos foram: Indisciplina na Escola, Bullying, Feminismo, Depressão na Adolescência, Suicídio na Adolescência e Religião e Mercantilismo da Fé.

Inicialmente, os alunos se dedicaram com muito empenho às pesquisas, traçaram os objetivos, realizaram as leituras indicadas, e nos momentos de orientação, definiram a metodologia de pesquisa que utilizariam - todos optaram pela revisão bibliográfica. Rapidamente, foram capazes de apresentar suas intenções por escrito. No entanto, com o andamento das etapas da pesquisa que estavam realizando e simultaneamente se desenvolviam as atividades escolares que concorriam com as investigações, os grupos deixaram de apresentar resultados concretos. Diante dessa avaliação, os pesquisadores do Grupo, que coordenavam a aplicação do Projeto, adotaram medidas pontuais como diálogos motivacionais, facilitaram a presença de voluntários e propuseram novas práticas de orientação. Dessa forma, constituiu-se um ambiente mais propício ao desenvolvimento das pesquisas dos alunos. Ficou patente que, para esse nível de ensino, a presença constante do orientador, incentivando e tutelando os alunos, foi fundamental, pois os alunos não tinham maturidade e hábito de organização de estudos que permitissem que eles desenvolvessem autonomamente atividades de pesquisa.

Durante todo o ano de 2019, foram desenvolvidas atividades como orientações gerais e particulares, palestras, sensibilização e rodas de conversa, para que os alunos pudessem dividir suas experiências com os colegas e partilhar suas dúvidas. Houve sessões de leitura, de escrita, de estudo e interpretação dirigida de textos, constituindo-se assim uma dinâmica que percorria diversas atividades, desde as aproximações mais gerais com os temas escolhidos até o aprofundamento dos estudos, com a utilização de artigos publicados em revistas acadêmicas 
reconhecidas e que tratavam das temáticas escolhidas pelos alunos. Todo o período de desenvolvimento da pesquisa foi marcado pela necessidade de acompanhamento constante dos alunos participantes do PIC pelos professores pesquisadores do GEPESP, orientadores e dos voluntários, o que indicou a falta de maturidade dos alunos para caminhar com autonomia na realização das atividades propostas.

No entanto, destacamos que uma característica muito presente nesses alunos é sua proatividade. Especialmente a turma, objeto dessa pesquisa, marcada pela intensa participação e aberta aos desafios, por isso acabou se filiando a inúmeros outros projetos paralelos oferecidos pela escola, como participação em peça de teatro, campeonatos, decoração da festa junina, entre outros, o que dificultou a concentração e foco dos alunos no projeto desenvolvido. Apesar dessas dificuldades, como resultado, esse projeto gerou um total de cinco trabalhos de conclusão produzidos pelos alunos com o apoio dos estagiários.

\section{A Pesquisa-ação desenvolvida com alunos do Ensino Médio}

A pesquisa com o desenvolvimento do Projeto de Iniciação Científica com a turma do Ensino Médio foi desenvolvida no ano de 2020, em uma escola pública estadual, localizada em município da Baixada Santista no Estado de São Paulo, integrante do Programa de Ensino Integral. O período de desenvolvimento da pesquisa ocorreu no período de fevereiro a outubro de 2020, incluindo assim o período no qual os alunos da escola pública paulista tiveram a suspensão das atividades presenciais em virtude da pandemia provocada pela COVID-19. Assim, as atividades, como orientações gerais e particulares e rodas de conversa, para que os participantes pudessem partilhar suas experiências com os colegas e compartilhar suas dúvidas, foram realizadas presencialmente até meados do referido mês e remotamente a partir desse período.

A pesquisa-ação foi desenvolvida com a participação de três pesquisadores do GEPESP e com apoio e participação direta da Gestão Escolar, que coordenava o grupo de alunos diretamente na escola, e a participação de um aluno de graduação voluntário do Ensino Superior. Todos os alunos que integraram a pesquisa cursavam a segunda série do Ensino Médio em uma escola pública estadual de um município da Baixada Santista ${ }^{5}$.

A escola em que foi realizada a investigação localiza-se em área central de um município integrante da região denominada Baixada Santista, no litoral do Estado de São Paulo, e atende a 318 alunos no Ensino Médio, em regime de período integral decorrente da implantação do Programa de Ensino Integral (PEI), a partir do ano de 2020. Por se tratar de implantação recente, a unidade escolar encontra-se em fase de adequação do ambiente, professores, alunos e funcionários. A unidade dispõe de boa infraestrutura, é bem equipada e organizada, procura divulgar e vivenciar valores éticos, de respeito, e valorizar o protagonismo juvenil, apresenta boa pontuação nas avaliações externas e é muito procurada pela comunidade.

Também, nessa etapa, a pesquisa foi realizada de uma perspectiva participativa com a adoção do modelo de pesquisa-ação e o objetivo proposto foi o de analisar em que medida o

\footnotetext{
${ }^{5}$ Reúne os municípios pertencentes tanto à Mesorregião de Santos (sobreposta à Microrregião de Santos) quanto à Mesorregião do Litoral Sul Paulista (mais precisamente, à Microrregião de Itanhaém). Todos os municípios da Região Metropolitana integram o litoral de São Paulo. É integrada por nove municípios: Bertioga, Cubatão, Guarujá, Itanhaém, Mongaguá, Peruíbe, Praia Grande, Santos e São Vicente.
} 
aluno desse nível de ensino pode responder aos requisitos de uma pesquisa científica, sendo capaz de produzir novos conhecimentos, desenvolver senso crítico, atuar em equipes, desenvolver leitura e escrita formais para o campo científico. Esses aspectos estão em consonância com o conjunto de leis que ordenam a educação brasileira, conforme já exposto.

A participação no projeto foi facultada a todos os alunos que cursavam a segunda série do Ensino Médio, e foram selecionados os doze mais interessados que participaram de uma palestra de sensibilização com a presença de professores, direção e pesquisadores do GEPESP. Desde o início da pesquisa, todos os alunos envolvidos foram informados de que a atividade não seria computada para nota e que poderiam optar por deixar de participar a qualquer momento, caso quisessem.

Considerando os princípios de ética na pesquisa e, também, que um dos princípios da pesquisa-ação é o da participação voluntária, na primeira reunião após serem expostos os objetivos e a sistemática de desenvolvimento do Projeto de Iniciação Científica que seria desenvolvido, foi dada liberdade de escolha aos alunos para que decidissem se continuariam no projeto. Um dos discentes entendeu que não dispunha de tempo para dedicação suficiente ao desenvolvimento da pesquisa e declinou da participação, os outros onze alunos se mantiveram no grupo que participaria do projeto.

$\mathrm{Na}$ segunda reunião, discutiu-se com eles qual seria o tema de seu interesse para o desenvolvimento da pesquisa que realizariam e optaram por pesquisar "os impactos da implantação do Programa de Ensino Integral na escola em que estudamos". Apresentaram como justificativa sua inserção em uma unidade PEI e que por isso seria relevante investigar entre os demais colegas o posicionamento da comunidade escolar a respeito do tema. Dessa forma, investigariam se a instituição estaria alinhada aos anseios de uma educação Integral e como a comunidade escolar receberia a instituição que acabara de ser implantada. Nessa ocasião, estabeleceu-se uma agenda de encontros e estudos prevendo a participação da direção e do universitário voluntário além dos pesquisadores do GEPESP. Os alunos dividiram-se em dois grupos, tendo cada um ficado responsável pelo estudo de um subtema e, ao final, haveria a união dos subtemas para a produção de um relatório de pesquisa e um artigo. Assim, cada um dos grupos dedicou-se a uma pesquisa específica, sendo uma delas sobre a implantação do PEI na própria escola e outra sobre a Educação Integral e História da Educação com foco na Educação Integral.

No entanto, logo após a realização da segunda reunião presencial, foi decretada quarentena no Estado de São Paulo e as escolas públicas suspenderam as atividades presenciais em virtude da pandemia provocada pelo COVID- $19^{6}$.

Em virtude dessa contingência e para não suspender as atividades que já haviam sido iniciadas, os pesquisadores optaram pelo uso de ferramentas de comunicação à distância com

\footnotetext{
${ }^{6}$ A esse respeito, recomendamos a leitura do texto, Escolas e a pandemia, ações de enfrentamento do afastamento educacional: uma investigação sobre as escolas durante o isolamento provocado pelo Coronavírus no período de março a maio, na Baixada Santista. Disponível em:

chrome-extension://oemmndcbldboiebfnladdacbdfmadadm/https://www.revi

vistas.usp.br/ceru/article/ download/174488/163252/433000.
} 
o uso de aplicativos como o Google Meet e o WhatsApp para as reuniões e orientações com a finalidade de manter o contato, a orientação e o acompanhamento das atividades. A adoção dessa medida foi essencial para a consecução da presente pesquisa, pois, como todos estavam isolados, o projeto teria que sofrer uma parada abrupta, que não ocorreu em virtude do uso dos aplicativos indicados e por meio do compartilhamento de documentos por e-mails. Portanto, a utilização de tais aplicativos foi de fundamental importância, pelo menos para a conclusão dos trabalhos iniciados presencialmente e levados a efeito de forma remota.

Verificou-se, no desenvolvimento da pesquisa com orientação e acompanhamento remoto, que o papel do orientador ficou especialmente trabalhoso. Exigiu paciência no aguardo das devolutivas, que se tornaram morosas e levaram mais tempo do que o esperado para as leituras dos autores e realização das atividades programadas. Foi necessário que a direção facilitasse o acesso aos dados e históricos relativos à unidade escolar.

Para colher as impressões da comunidade escolar sobre a implantação do PEI, os alunos participantes do PIC desenvolveram um questionário que foi encaminhado pelo e-mail da escola aos alunos do Ensino Médio, porém não foram devolvidos em número representativo para realização da análise pretendida. Simultaneamente à realização da pesquisa dos alunos do PIC, a Secretaria da Educação do Estado de São Paulo aplicou um questionário ${ }^{7}$ sobre o desenvolvimento do PEI na escola com número significativo de respostas. Esses dados foram disponibilizados pela escola e aproveitados pelos alunos do PIC, de modo a enriquecer sua pesquisa.

Ao longo do desenvolvimento do projeto, avaliamos que, em decorrência das dificuldades representadas pela adoção de orientação e acompanhamento remoto, dos onze alunos que iniciaram, apenas três permaneceram no projeto e concluíram essa etapa da investigação. Mesmo com o projeto de iniciação científica fragilizado pelo abandono de parte significativa dos alunos, os integrantes do GEPESP, em conjunto com a direção da unidade escolar, avaliaram que não seria correto suspender o Projeto e decidiram dar continuidade à pesquisa de forma remota. As orientações passaram a ser direcionadas aos três participantes remanescentes e, a partir daí, a participação ativa do voluntário e da direção da unidade escolar tornou-se indispensável de modo a apoiar o trabalho dos alunos.

Apesar desses elementos, foi possível desenvolver parte significativa da pesquisa possibilitando um aprofundamento do conhecimento dos alunos participantes da proposta de ensino Integral implantada e especialmente da realidade da Escola que frequentam, assim como o reconhecimento da importância da pesquisa e a produção de um texto que avaliamos como muito significativo para futuros estudos sobre a implantação do programa de Educação Integral e especialmente para o desenvolvimento da autonomia e protagonismo dos estudantes envolvidos.

Apesar das dificuldades enfrentadas com a pandemia, a decretação do regime de quarentena no Estado de São Paulo e a necessidade de desenvolvimento de um modelo de orientação ao PIC realizado remotamente, o resultado da atividade foi muito promissor, pois os alunos desenvolveram um relatório de pesquisa consubstanciado com pesquisa realizada à

\footnotetext{
${ }^{7}$ A Secretaria de Educação do Estado de São Paulo realiza regularmente avaliação sobre o PEI. Essa avaliação é denominada Ciclo de Aperfeiçoamento e Formação (CAF) e aplicada a todos os segmentos escolares, tendo como objetivo inventariar as impressões a respeito da escola e do Programa. Após a realização do levantamento, as escolas recebem seus resultados.
} 
distância com os alunos da escola, com utilização de ferramenta de pesquisa remota expondo a percepção dos alunos a partir da implantação do Ensino Integral na escola, e também indicaram a intenção do grupo em continuar no ano de 2021 a desenvolver um projeto de pesquisa na escola.

\section{Considerações finais - Uma análise preliminar}

David Tripp (2005, p.443), em seu texto sobre pesquisa-ação, alerta que há limitações no ambiente escolar relativo a diversos fatores, como o tamanho das classes, ausência de participação dos pais, a organização do tempo docente, entre outros. Nos dois anos de desenvolvimento da pesquisa-ação, apesar de ser em níveis de ensino diferentes e apesar do acompanhamento constante dos orientadores e estagiários, constatamos que parte dos alunos perdeu o foco nos trabalhos de pesquisa e alguns alunos, ao longo da pesquisa, expressaram o desejo de abandonar o projeto, o que demandou a necessidade de atendimento individualizado. Assim, exigiu-se muito esforço para manter o foco dos estudantes nas atividades do projeto. Ao longo do desenvolvimento das atividades, os pesquisadores tiveram que reorganizar os cronogramas iniciais do desenvolvimento das pesquisas dos alunos, com a finalidade de as ajustar a outras atividades desenvolvidas pela escola e aos períodos de realização de avaliações na escola, garantindo assim a continuidade da realização das pesquisas.

Observou-se que, embora em geral os alunos participantes escrevam relativamente bem, ainda não se encontram devidamente familiarizados com a escrita formal de um artigo científico e apresentaram dificuldade no preparo dos relatórios finais. Houve falta de domínio do vocabulário técnico especializado dos vários temas pesquisados, o que dificultou e tornou mais demorado o processo de entendimento durante a leitura dos artigos científicos por eles selecionados sobre os temas, inclusive pela complexidade dos temas tratados.

No ano de 2020, devido ao cenário do isolamento social e suspensão das atividades presenciais, constatamos que a frequência dos alunos às reuniões virtuais diminuiu de maneira drástica, caindo de onze para três alunos, mesmo com o uso do aplicativo Google Meet e WhatsApp para as reuniões e orientações. Nessas condições, não foi possível a realização dos procedimentos de acompanhamento e observação "in loco" preconizados pela metodologia da pesquisa-ação, que pressupõe contato e participação presencial entre os pesquisadores e integrantes do projeto com a realização de diálogos e intervenção que não foram possíveis de modo convencional.

Observamos que, com a adoção de um modelo de comunicação à distância, que o grupo foi obrigado a incorporar, apesar de ter sido providencial para que pudéssemos dar continuidade ao projeto, constituiu-se um dificultador para o estabelecimento do diálogo, pois os atores estão inseridos em ambientes diversos que dificultam o fortalecimento das relações intragrupo. Quando comparado ao modelo presencial de orientação utilizado em 2019, fica ainda mais evidente a dificuldade de constituir relações de engajamento e pertencimento dos alunos.

Avaliamos que, no período de 2020, o afastamento social e a necessária adoção de um modelo de orientação à distância geraram o empobrecimento das relações de orientação presencial, que cria laços e envolvimento. Avaliamos que esse elemento foi o principal responsável pelo distanciamento dos participantes e consequente abandono do grupo por alguns deles apesar das tentativas empreendidas pelos pesquisadores do GEPESP e da gestão da escola 
para que continuassem participando da pesquisa. Um dos elementos que permitem que façamos essa afirmação é que na experiência de iniciação científica desenvolvida pelo GEPESP na escola de ensino fundamental no ano de 2019, as reuniões presenciais com a presença dos pesquisadores, os diálogos e a presença do universitário voluntário ajudaram a manter nos participantes a disposição de participar e produzir durante a experiência.

$\mathrm{Na}$ investigação em tela, há um conjunto de experiências a ser partilhado por todos os envolvidos, englobando ensinamentos, experiências, valores, estímulo e busca de objetivos comuns. Embora seu objetivo geral seja responder às indagações inicialmente propostas pelo grupo de pesquisa, um dos objetivos específicos é o objetivo geral do Projeto de Iniciação Científica, que é o de propiciar aos alunos de educação básica envolvidos no projeto a vivência do desenvolvimento de um experimento científico completo.

Assim, ao longo do desenvolvimento desse projeto, foi realizado com docentes e alunos um conjunto de ações englobando a pesquisa e discussão de conteúdo, técnicas, experiências e valores da pesquisa científica, que teve como principal resultado junto aos participantes a possibilidade de vivência de um experimento científico desde a definição do tema/problema de pesquisa até a redação de textos com a exposição dos resultados das pesquisas desenvolvidas pelos alunos. Foi, portanto, uma atividade que reputamos muito rica na formação desses alunos nos dois níveis de ensino e no desenvolvimento de um olhar mais sensível pelo corpo docente e da gestão das escolas sobre a possibilidade de desenvolvimento de pesquisas pelos alunos e do seu importante papel no desenvolvimento da produção textual, maturidade e aprendizagem dos alunos.

\section{Referências bibliográficas}

BRASIL. Constituição (1988). Constituição Federativa do Brasil. Brasília, DF: Senado Federal: Centro Gráfico, 1988.

BRASIL. Ministério da Educação e Cultura. - LEI No 9394/96, de 20-12- 1996. Estabelece as diretrizes e bases da Educação Nacional. Brasília: MEC, 1996.

BRASIL. Ministério da Educação, Instituto Nacional de Estudos e Pesquisas Educacionais Anísio Teixeira (INEP). Mapa do analfabetismo no Brasil. Imprensa Oficial. Brasília, s/d.

BRASIL. Ministério da Educação e Cultura. Lei 4.024 de 20 de dezembro de 1961. Fixa as Diretrizes e Bases da Educação Nacional. Brasília: Distrito Federal. 1961. Disponível em: https://presrepublica.jusbrasil.com.br/legislacao/108164/lei-de-diretrizes-e-base-de-1961-lei4024-61. Acesso em: 26 out. 2020.

DIAS, Ana Maria Lorio; PASSOS, Carmensita Matos Braga. Passado e presente na formação de professores: por entre perspectivas históricas, legais e políticas. Revista Internacional de Formação de Professores (RIFP), Itapetininga, v. 1, n.2, p.85-108, 2016.

SÃO PAULO (Estado) Secretaria da Educação. Material de apoio ao Programa Ensino Integral do Estado de São Paulo. Diretrizes do Programa Ensino Integral. Caderno do Gestor. $1^{\text {a }}$ edição. São Paulo: SE, 2014.

SÃO PAULO (Estado) Secretaria da Educação. Documento Formação Básica - Modelo Pedagógico. Disponível em: https://midiasstoragesec.blob.core.windows.net/001/201 9/08/deitr-ensino-integral_modelo pedaggico.pdf. Acesso em: 25/10/2020. 
SOUZA, Roger M. Q.; COUTO, José C. D.; BROVINI, Cristiane N. Iniciação científica no Ensino Fundamental na prática - aproximações iniciais. International Studies Coepta 3-4 (International Studies on Law \& Education 34-45) jan-ago 2020 Cemoroc-Feusp / IJI - Univ. do Porto / Colégio Luterano São Paulo. Disponível em: http://www.hottopos.com/isle34_35/65-72RogerZkCrs.pdf> Acesso em: 2 out. 2020.

LAKATOS, Eva Maria; MARCONI, Marina de Andrade. Fundamentos de metodologia científica. $5^{\mathrm{a}}$. ed. São Paulo: Atlas, 2003.

THIOLLENT, Michel. Metodologia da pesquisa-ação. São Paulo: Autores Associados, 1986 (Coleção Temas Básicos de Pesquisa-Ação).

TRIPP, David. Pesquisa-ação: uma introdução metodológica. Educ. Pesquisa. São Paulo, v. 31, n. 3, p. 443-466, dezembro de 2005. Disponível em: http://dx.doi.org/10.1590/S151797022005000300009. Acesso em: 20 ago. 2019.

VALENTINI, Camila Altmayer; ZUCCHETTI, Dinora Tereza. Educação Integral no Brasil: das experiências históricas ao Programa Mais Educação. Revista Comunicações. PPGE UNIMEP. Piracicaba, v. 24 n. 2 p. 199-214, maio/ago. 2017. 